\title{
Distribution of Hairs on the Phalanges of Hands among Ghanaians
}

\author{
Benjamin Aboagye, Korantema Mawuena Tsegah, and Abdala Mumuni Ussif \\ Department of Biomedical and Forensic Sciences, School of Biological Sciences, University of Cape Coast, Cape Coast, Ghana \\ Correspondence should be addressed to Benjamin Aboagye; baboagye@ucc.edu.gh
}

Received 16 April 2013; Accepted 3 July 2013

Academic Editor: Tetsuo Katsuura

Copyright ( 2013 Benjamin Aboagye et al. This is an open access article distributed under the Creative Commons Attribution License, which permits unrestricted use, distribution, and reproduction in any medium, provided the original work is properly cited.

\begin{abstract}
Aim. The study intended to observe the frequency and pattern of distribution of phalangeal hairs on the hands of Ghanaians. Material and Methods. A total of 1040 healthy consenting individuals (529 females and 511 males) aged between 18 and 45 years were randomly selected from the University of Cape Coast Community. Presence or absence of phalangeal hairs was observed with the aid of a pocket lens. Results. Hairs were observed on the proximal phalanges of $98.24 \%$ of the males and $96.22 \%$ of the females. The most common hair pattern observed on the proximal digits was $2-3-4-5$ (65.95\% males and $70.32 \%$ females). The highest frequency of midphalangeal hairs occurred in the group with hair on the 4 th digit alone (3.33\% males and $2.27 \%$ females) followed by the 3-4-5 group (2.54\% males and 1.89\% females). Conclusion. Females have lower frequency of phalangeal hairs than males. The outcome of this study may be significant medicolegally and in anthropological racial and gender studies.
\end{abstract}

\section{Introduction}

The hair is an epidermal derivative of the skin which offers protection against mechanical injury in mammals. It is of great interest to clinicians and biomedical scientists because of its many useful biological functions, including dispersion of sweat gland products [1]. Hair has accompanied human development since antiquity as a symbol of power, dominance, and strength [2] and has been seen as a thing of beauty and a tool for sexual communication [3].

The study of body hair distribution has attracted the interest of anthropologists for ages. Of particular interest is phalangeal hair distribution. Danforth [4] pioneered the study of distribution of hairs on the digits of humans and suggested genetic influence. Since then, many investigators have studied phalangeal hair distribution on the basis of gender, race, and ethnicity [5-9]. Such studies have shown that most individuals have hair on the proximal phalanges, while few people in a population have hairs on the middle phalanges. Complete absence of hairs on the middigits of hand is a recessive trait [10], and inheritance of the gene responsible for phalangeal hair growth and distributions is done in Mendelian fashion [11]. The presence or absence of hairs on middle phalanges is controlled by a single allelic gene, and Bernstein and Burks [11] have hypothesized five pairs of alleles $\left(A_{0}, A_{1}, A_{2}, A_{3}\right.$, and $\left.A_{4}\right)$ with subscripts representing the digits staring from the thumb. As a result, middigital hair has been used to demonstrate basic genetics, an idea which is opposed by McDonald [12]. In their review of the literature on midphalangeal hair distribution, Egesi and Rashid [13] explored the clinical relevance of the trait as a putative marker that will inform clinical treatment of people of different ancestry. According to the authors, females who have high midphalangeal hair count experience less adverse clinical and psychological effects of oral contraceptives. A good knowledge about phalangeal hair distribution will help clinicians in tailoring treatment to obtain desired clinical outcome.

The numerous literatures on phalangeal hair distributions are based on people from Europe and Asia. Except for the few known publications among Nigerians [7, 12, 14-16], there is little report based on Africans, and there seem to be no publication at all among the Ghanaian population. This study intends to assess the presence or absence and different patterns of hair distribution on the phalanges of the population. 
TABLE 1: Combination of fingers with hair on the proximal phalanges.

\begin{tabular}{lcccc}
\hline \multirow{2}{*}{ Hair patterns } & \multicolumn{2}{c}{ Males } & \multicolumn{2}{c}{ Females } \\
& Number & $\%$ & Number & $\%$ \\
\hline $1-2-3-4-5$ & 120 & 23.48 & 90 & 17.01 \\
$2-3-4-5$ & 337 & 65.95 & 372 & 70.32 \\
$2-3-4$ & 3 & 0.59 & - & 0.00 \\
$3-4-5$ & 32 & 6.26 & 37 & 6.99 \\
$3-4$ & 7 & 1.37 & 4 & 0.76 \\
3 & 2 & 0.39 & 3 & 0.57 \\
4 & 1 & 0.20 & 3 & 0.57 \\
Without hairs & 9 & 1.76 & 20 & 3.78 \\
\hline Total & 511 & 100 & 529 & 100 \\
\hline
\end{tabular}

\section{Material and Methods}

The study participants were randomly selected from the University of Cape Coast Community, all of which were of Ghanaian descent. A total of 1040 healthy consenting individuals comprising 529 females and 511 males aged 1845 years were recruited from November, 2012 to March, 2013. The presence or absence of hair on the proximal and middle phalanges was observed using a hand lens. Observations made were recorded with respect to age, sex, and phalanges. Analysis of data was done using SPSS (version 16.0, SPSS Inc., Chicago, IL, USA) for frequencies and percentages. Fisher's exact test was done to determine gender differences in presence or absence of midphalange hairs using GraphPad Prism version 5.0, and a $P$ value $<0.05$ was considered statistically significant.

\section{Results}

Hair was present on the proximal phalanges in $98.24 \%$ of males and $96.22 \%$ of females. Pattern of distribution of hair on proximal phalanges is represented in Table 1. Some individuals had hair on the proximal digit of only the 3rd or 4 th digit. The most common pattern was 2-3-4-5 in both sexes $(65.95 \%$ males and $70.32 \%$ females). The frequency of combination of 2-3-4 was observed in $3(0.59 \%)$ males but none in females. The number of individuals without hair on the phalanges was higher in females $(3.78 \%)$ than males $(1.76 \%)$.

Midphalangeal hairs were observed in $9.00 \%$ of males and $6.99 \%$ of females (Table 2). However, there was no observed significant differences in this observation $(P=$ 0.2533 ). Combination of fingers with midphalangeal hairs is illustrated in Table 3. The highest frequency of midphalangeal hairs occurred in the group with hair on the 4th digit alone (3.33\% males and $2.27 \%$ females). The next highest was in the 3-4-5 group (2.54\% males and $1.89 \%$ females). In the various groups, hair on the 4 th phalanx was common totaling $8.81 \%$ in males and $7.00 \%$ in females. Distal phalanges did not have hair on them.
TABLE 2: Frequency of individuals with and without hair on middle phalanges.

\begin{tabular}{lcccccc}
\hline \multirow{2}{*}{ Sex } & \multicolumn{2}{c}{ Presence of hair } & \multicolumn{2}{c}{ Absence of hair } & \multicolumn{2}{c}{ Total } \\
& Number & $\%$ & Number & $\%$ & Number & $\%$ \\
\hline Male & 46 & 9.00 & 465 & 91.00 & 511 & 100 \\
Female & 37 & 6.99 & 492 & 93.01 & 529 & 100 \\
\hline
\end{tabular}

\section{Discussion}

Earlier reports show that the majority of individuals have hair on the proximal phalanges of the hand but none on the distal phalanges. In the present study, $1.76 \%$ male and $3.78 \%$ female participants had no hairs on any of the phalanges. This outcome is similar to the study of Hatiboglu [5] who reported $0.2 \%$ absence of phalangeal hairs in males and $1.7 \%$ absence in females. A study among Indian population also reported higher frequency of phalangeal hair absence in females $(2 \%)$ than in males $(0.8 \%)$ [9]. Similar lower incidence of phalangeal hairs in females (85.1\%) than males (99.3\%) has been found among the Chinese [17]. On the contrary, some authors have reported $0.0 \%$ incidence of phalangeal hair absence among Nigerian females $[15,16]$. The most common pattern of proximal digit hairs in this study was 2-3-4-5 which is in corroboration with findings of other authors $[8,14,16]$. Studies among Asians have shown the 1-2-3-4-5 combination to be higher than the 2-34-5 pattern $[9,18]$, an observation different from this study. These differences can be attributed to genetic factors that influence hair growth on the phalanges [11] and environment. Although few publications are available, observations made among Ghanaians and Nigerians might prove that the 2-3-4-5 pattern is a characteristic of black Africans. This information might be very relevant in population studies [19].

The frequency of occurrence of midphalangeal hair is higher in males than females. Generally, females have low incidence of phalangeal hairs. This observation is supported by literature in different populations-Turks [5]; Tibetans [6]; Nigerians [8]; and Serbians [20]. The kind of work one does has influence on presence or absence of phalangeal hairs $[8,15]$. Manual work involving continuous use of hands subjects the hairs to wear and tear that can cause them to be lost. Women who are always working by the fire are expected to have lower occurrence of phalangeal hairs than men. The participants involved in this study were largely students and some teaching staff, although this does not preclude them from engagement in one manual work or the other. The students may be engaged in farming, domestic cooking, and washing that might influence phalangeal hair distribution. However, the kind of work engaged by study participants was not considered. Therefore, the results obtained from this study may not necessarily represent phalangeal hair distribution of Ghanaians who are not engaged in manual labour.

The highest common digit combination of midphalangeal hair in both sexes was the presence of hair only on the fourth digit (ring finger) and was seen in 3.33\% males and $2.27 \%$ females. Low percentages reported here do not deviate from 
TABLE 3: Combination of fingers with hair on middle phalanges.

\begin{tabular}{lcccccccccccrrr}
\hline \multirow{2}{*}{ Sex } & \multicolumn{2}{c}{$2-3-4-5$} & \multicolumn{2}{c}{$3-4-5$} & \multicolumn{2}{c}{$3-4$} & \multicolumn{2}{c}{$4-5$} & 4 & & 5 & \multicolumn{2}{c}{ Total } \\
& Number & $\%$ & Number & $\%$ & Number & $\%$ & Number & $\%$ & Number & $\%$ & Number & N & Number & $\%$ \\
\hline Male & - & 0.00 & 13 & 2.54 & 4 & 0.78 & 11 & 2.15 & 17 & 3.33 & 1 & 0.20 & 46 & 9.00 \\
Female & 3 & 0.57 & 10 & 1.89 & 4 & 0.76 & 8 & 1.51 & 12 & 2.27 & - & 0.00 & 37 & 7.00 \\
\hline
\end{tabular}

Yoruba Nigerians (0.2\%) [8]. The percentage occurrence of midphalangeal hairs is smaller than reports in Caucasian and Asian populations $[5,16]$, which confirms the claim that there is a striking population difference in mid-phalangeal hair distribution, with Africans having the lowest frequency and the white race having the highest [7].

\section{Summary}

The presence or absence of hairs on the phalanges of Ghanaians was studied among staff and students (511 males and 529 females) of the University of Cape Coast aged between 18 and 45 years. Frequency of occurrence of hairs on the proximal (98.24\% males and $96.22 \%$ females) and middle (9.00\% males and $6.99 \%$ females) phalanges was higher in males than in females. Common pattern of proximal phalangeal hairs in both sexes was 2-3-4-5 which is similar to what has been reported among Nigerians. The outcome of this study may be significant medicolegally and in anthropological racial and gender studies.

\section{Conflict of Interests}

There is no conflict of interests with any of the software used in data analysis.

\section{Acknowledgments}

The authors acknowledge the support of the Head of Department of Biomedical and Forensic Sciences, University of Cape Coast-Dr. Johnson Nyarko Boampong for providing the enabling environment for the research to be conducted. The staff and students involved in this study are also appreciated for availing themselves.

\section{References}

[1] R. Paus and G. Cotsarelis, "The biology of hair follicles," The New England Journal of Medicine, vol. 341, no. 7, pp. 491-497, 1999.

[2] C. Popescu and H. Höcker, "Hair-the most sophisticated biological composite material," Chemical Society Reviews, vol. 36, no. 8, pp. 1282-1291, 2007.

[3] V. A. Randall, "Hormonal regulation of hair follicles exhibits a biological paradox," Seminars in Cell and Developmental Biology, vol. 18, no. 2, pp. 274-285, 2007.

[4] C. H. Danforth, "Distribution of hair on the digits in man," American Journal of Physical Anthropology, vol. 4, pp. 189-204, 1921.

[5] M. T. Hatiboglu, "The hair distribution of the phalanges of the hand among Turks," Journal of Anatomy, vol. 137, no. 3, pp. 537540, 1983.
[6] S. C. Tiwari and M. K. Bhasin, "A note on the distribution of middle phalangeal hair among Tibetans," American Journal of Physical Anthropology, vol. 31, no. 3, pp. 429-432, 1969.

[7] J. D. Singh, "Distribution of hair on the phalanges of the hand in Nigerians," Acta Anatomica, vol. 112, no. 1, pp. 31-35, 1982.

[8] A. O. Olabiyi, A. O. Akpantah, O. F. Oyerinde, S. C. Gbotolorun, M. A. Eluwa, and T. B. Ekanem, "The distribution of hair on the phalanges of a sample population of Nigerian Yorubas in relation to sex, age and job type," Nigerian Journal of Physiological Sciences, vol. 23, no. 1-2, pp. 101-104, 2009.

[9] M. R. Sangam, S. S. S. Devi, K. Krupadanam, and K. Anasuya, "A study of distribution of hair on the phalanges of the hand in Andhra Pradesh, India," Journal of Clinical and Diagnostic Research, vol. 6, no. 4, pp. 553-556, 2012.

[10] L. Beckman and J. A. Book, "Distribution and inheritance of mid-digital hair in Sweden," Hereditas, vol. 45, pp. 215-220, 1959.

[11] M. M. Bernstein and B. S. Burks, "The incidence and mendelian transmission of mid-digital hair in man," Journal of Heredity, vol. 33, no. 2, pp. 45-53, 1942.

[12] J. H. McDonald, Myths of Human Genetics, pp. 51-53, Sparky House, Baltimore, Md, USA, 2011, http://udel.edu/ mcdonald/ mythdigithair.html.

[13] A. Egesi and R. Rashid, "Hair in the middle phalanges: clinical significance," Journal of Cosmetic Dermatology, vol. 9, no. 4, pp. 325-330, 2010.

[14] F. E. Mbajiorgu, S. A. Asala, A. B. Ejiwunmi, and Z. Abdullahi, "Hair distribution on the phalanges of the hand among Kanuris and Baburs/Buras of North-Eastern Nigeria," Acta Anatomica, vol. 157, no. 4, pp. 324-329, 1996.

[15] O. O. Oyerinde, O. O. Oyerinde, and O. L. Olaitan, "Phalangeal hair distribution among field and office workers in western part of Nigeria: implications for health and safety of worker," Journal of Sociology and Education in Africa, vol. 8, no. 1, pp. 1-16, 2009.

[16] F. M. Onyije and C. A. Oyinbo, "Hair distribution on the phalanges of the hand in the Ogba tribe in the rivers state, Niger Delta region of Nigeria," Asian Journal of Biological Sciences, vol. 4, no. 3, pp. 277-281, 2011.

[17] A. S. Dharap, B. C. Lim, and L. B. Ong, "Distribution of hair on the dorsum of the phalanges of the hand in a Chinese population from Malaysia," Anthropologischer Anzeiger, vol. 54, no. 4, pp. 311-316, 1996.

[18] S. Ali, N. Sharma, R. S. Mandloi, and D. Usmani, "A study of distribution of hair on the phalanges of hand in north india," Innovative Journal of Medical and Health Science, vol. 3, no. 1, pp. 26-28, 2013.

[19] S. M. Garn, "The use of middle-phalangeal hair in population studies," American Journal of Physical Anthropology, vol. 9, no. 3, pp. 325-334, 1951.

[20] M. Nesic, S. Cicevi, M. Ciric, and V. Nesic, "Middle phalangeal hair distribution in Serbian high school students," Archives of Biological Sciences, vol. 62, no. 3, pp. 841-850, 2010. 

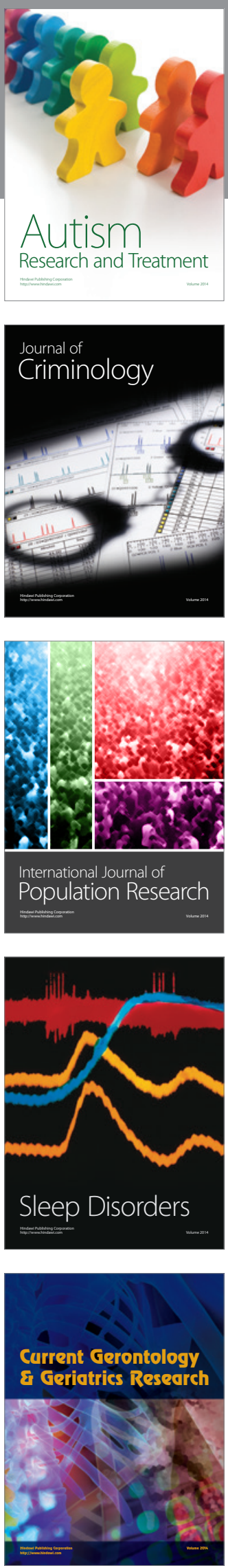
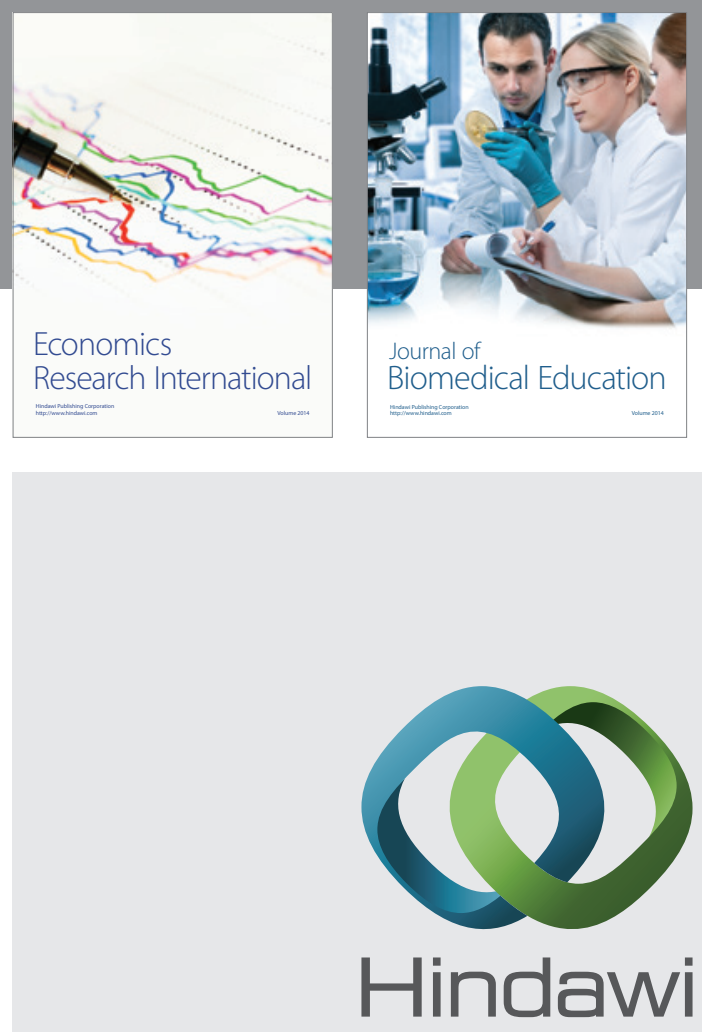

Submit your manuscripts at

http://www.hindawi.com
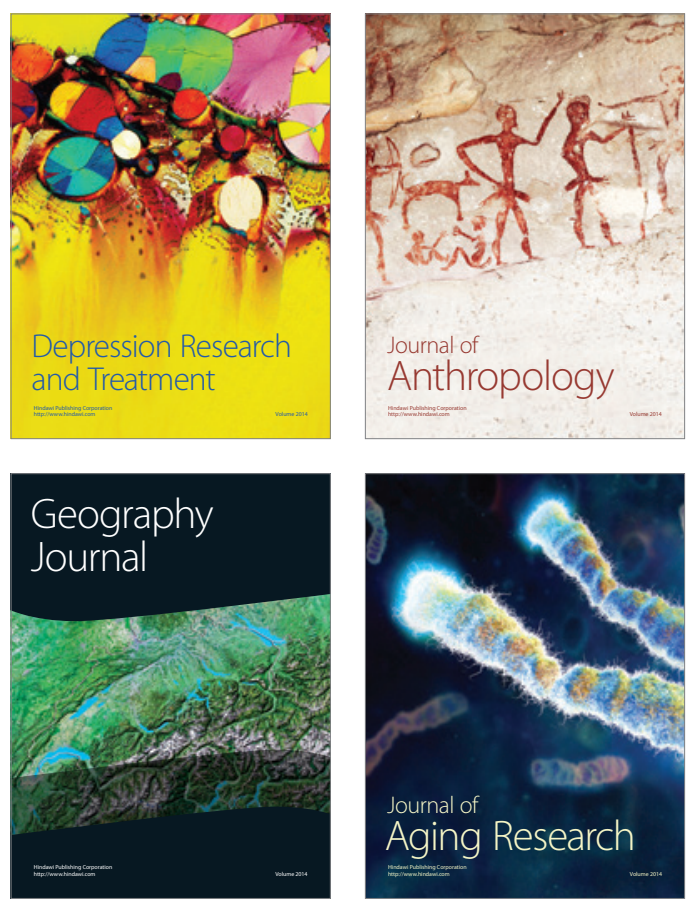
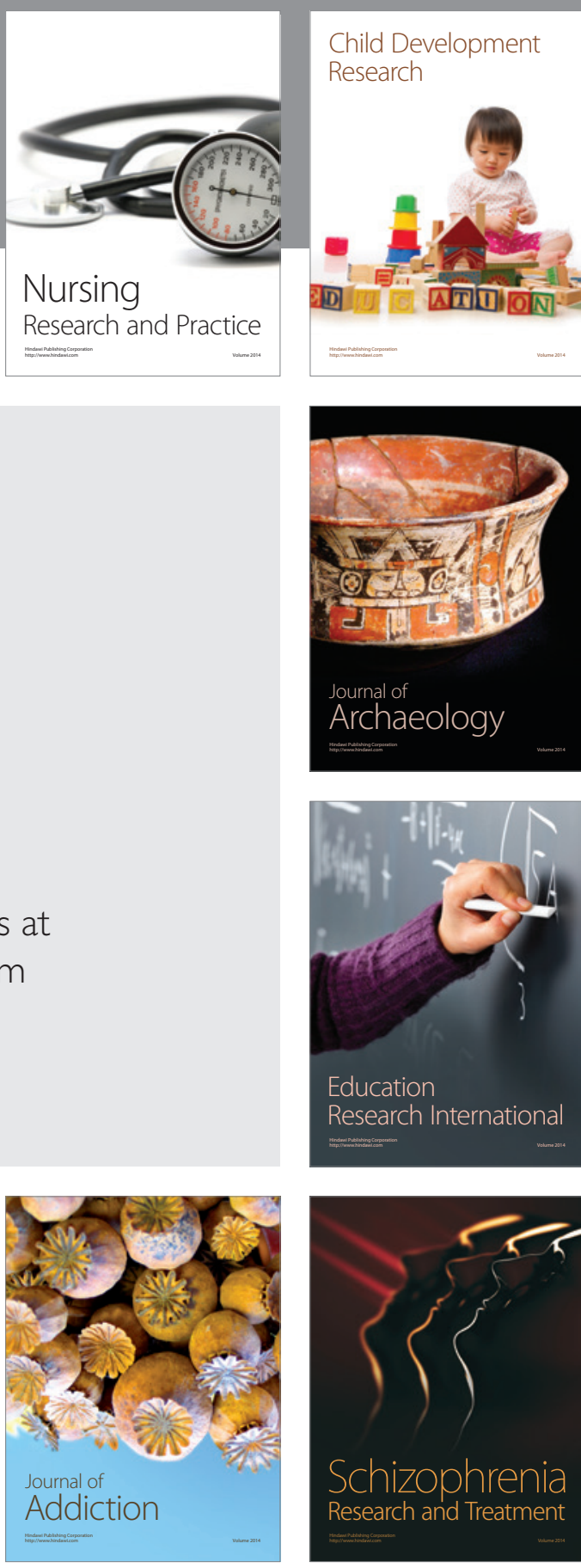

(D)
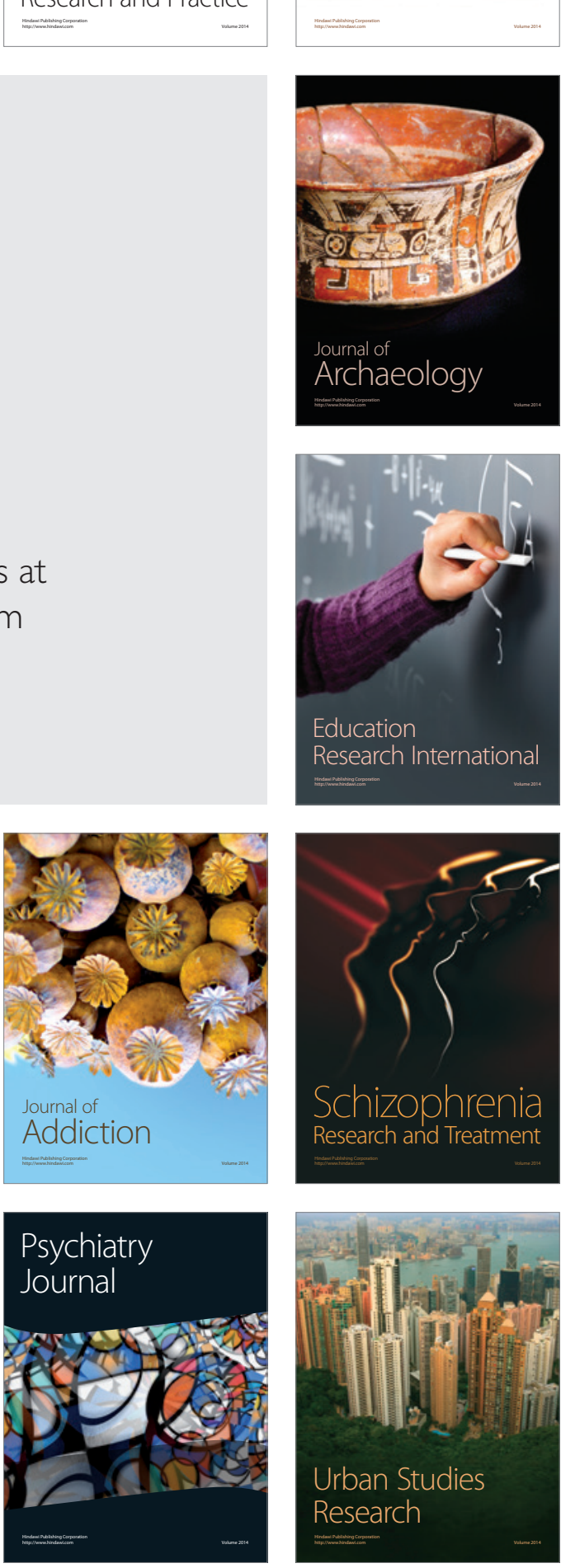